Nig. J. Biotech. Vol. 36 (2) : 95 - 113 (Dec 2019)

ISSN: 01891731

Available online at

http://www.ajol.info/index.php/njb/index

and www.biotechsocietynigeria.org

DOI: https://dx.doi.org/10.4314/njb.v36i2.11

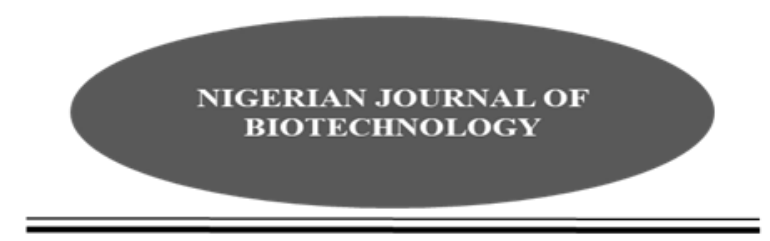

\title{
Utilization of Airlift Fermenters in the Mass Propagation of Pseudomonas and Aureobasidium Species for the Bioremediation of Crude Oil Polluted Aquatic Environments
}

\author{
${ }^{1}$ Ejianreh, E. L., ${ }^{* 1}$ Aransiola, E. F., ${ }^{1}$ Adebimpe, A. I. and ${ }^{1}$ Solomon, B. 0. \\ ${ }^{1}$ Department of Chemical Engineering, Obafemi Awolowo University, Ile-Ife, Nigeria
}

\begin{abstract}
This study involved the design and fabrication of airlift fermenters for the mass propagation of a consortium of three microorganisms (Pseudomonas aeruginosa, Pseudomonas fluorescence and Aureobasidium pullulans). The efficacy of the blend in the bioremediation of simulated crude oil polluted water systems environments was also tested with a view to generating more data on crude oil degrading microorganisms for bioremediation purposes. The organisms were separately grown on a gyratory shaker at $120 \mathrm{rpm}$ and at $30{ }^{\circ} \mathrm{C}$ until notable growths were observed. Equal volume of the grown organisms $(500 \mathrm{ml})$ of mixed culture was used as inoculum for the $4.5 \mathrm{~L}$ of medium in the $7 \mathrm{~L}$ airlift fermenter. Thereafter, this was transferred into the 45 litres medium in the $\mathbf{7 0} \mathrm{L}$ fermenter until significant growth was observed at room temperature. Culture broths were withdrawn at intervals for the determination of biomass and residual hydrocarbon concentrations. The product from the $\mathbf{7 0} \mathrm{L}$ fermenter was introduced into simulated polluted water systems from which samples were withdrawn weekly. Analyses for residual hydrocarbon contents were carried out using appropriate analytical techniques. The results showed that $\mathbf{7 8 . 5 \%}$ hydrocarbon removal was observed in the $\mathbf{7} \mathrm{L}$ fermenter after $\mathbf{7 2} \mathrm{h}$, while that of the $70 \mathrm{~L}$ fermenter was $\mathbf{9 7 . 8 \%}$ after $180 \mathrm{~h}$ of fermentation. Polluted water sample treated with the microbes experienced $96.4 \%$ removal after 10 weeks of treatment. It was observed further that the application of NPK fertilizer biostimulant aided microbial activities in the removal of petroleum hydrocarbons than urea, cow dung and poultry droppings. The study has demonstrated that effective bioremediation of crude oil polluted water systems could be achieved through the application of biostimulants with mass propagated crude oil degrading organisms using airlift fermenter systems.
\end{abstract}

Keywords: Pseudomonas aeruginosa; Pseudomonas fluorescence; Aureobasidium pullulans; Airlift fermenter; Bioremediation; Biostimulation; Bioaugmentation.

*Corresponding Author's Email Address: aransiolaef@gmail.com 


\section{Introduction}

Crude oil, found in porous rock formations in the earth's crust, is extracted for utilization as fuel or for processing into chemical products (Cohen, 2002, Britannica, 2018). They contain a complex mixture of saturates, aromatics, resins and asphaltenes and the weight percent of carbon and hydrogen in these mixtures range from $82-87$ wt. $\%$ and $12-15$ wt.\% respectively (Balba et al., 1998, Britannica, 2018). Seepage from natural deposits and accidental spills during the production, transportation, storage and refining of petroleum products are the major routes by which petroleum enters the environment (Balba et al., 1998, Cameotra and Singh, 2008). These releases present a long term threat to all forms of life in the marine and terrestrial environments (Balba et al., 1998). Several microbes have the capacity to metabolize or biodegrade oil in order to take up energy for their growth, though the rates at which they naturally degrade them is exceedingly slow (Mehrasbi et al., 2003, Omotayo et al., 2012, Ron and Rosenberg, 2014). These microbes include bacteria and yeast as the dominant degraders in aquatic environments and fungi and bacteria in soil environments and their abilities to degrade oil have been reported in several major review papers (Atlas and Raymond, 1977, Higgins and Gilbert, 1978, Leahy and Colwell, 1990, Hanson et al., 1997, Balba et al., 1998). It is generally believed that the complex mixtures of oil can be better effectively biodegraded by communities of microorganisms acting as a consortium due to the various enzyme systems required for their complete mineralization which may not be present in a single organism (Colwell et al., 1977, Balba et al., 1998, Ron and Rosenberg, 2014). It has been reported that Pseudomonas aeruginosa and Pseudomonas fluorescence are very efficient degraders of hydrocarbons (Barathi and Vasudevan, 2001, Barathi and Vasudevan, 2003, Das and Mukherjee, 2005, Das and Mukherjee, 2007, Thavasi et al., 2011) while Aureobasidium pullulans has not been previously reported to be used in the bioremediation of crude oil polluted environment. However, ensuring adequate microbial population of the consortium of organisms at the polluted environment remains a major challenge. Bioaugmentation and biostimulation are thus needed to enhance the rate of oil biodegradation. While bioaugmentation significantly enhances the rate of bioremediation by increasing the microbial population at the polluted sites (Atlas, 1981, Thomassin-Lacroix et al., 2002, Lin et al., 2010), biostimulation supplies the required nutrients mainly nitrogen and phosphorus sources or biosurfactants to the polluted sites (Mulligan, 2005, Whang et al., 2008, Lin et al., 2010). In this work, bioaugmentation was achieved with the use of airlift bioreactors (ALB) due to the advantage of ALB over bubblecolumn and stirred bioreactors which include reduced cell damage, higher oxygen and mass transfer rates, lower energy cost, simpler construction and no mechanical agitation (Chisti and Jauregui-Haza, 2002, Kilonzo et al., 2006, Lizardi-Jiménez et al., 2015). Thus, this work aims to explore the use of airlift fermenters to mass propagate microbes for application in biostimulated and bioaugumented remediation operations in aquatic environment.

\section{Materials and Methods \\ Materials}

The various materials used for the study were: $\mathrm{n}$ hexane, ethanol, sodium hypochlorite $(\mathrm{NaOCl})$, mineral salts for medium formulation, nutrient agar and malt extract agar which were all of analytical grade. The three microorganisms (Pseudomonas aeruginosa, Pseudomonas fluorescence, Aureobasidium pullulans) utilized in this study were obtained from the collections in the Department of Microbiology, Obafemi Awolowo University. The crude oil used was obtained from Nigerian Petroleum Development Company Limited (NPDC), Benin City, Edo State while the fresh river water utilized in this study was obtained from Opa River flowing across Sir Adesoji Aderemi Road situated in Obafemi Awolowo University campus, Ile-Ife. Biostimulants used are urea and NPK (Nitrogen, Phosphorus, Potassium) 15:15:15 fertilizer purchased from Tobal Nigeria Ltd., Ibadan together with poultry droppings and cow dungs obtained from Obafemi Awolowo University Teaching and Research farm, Ile-Ife.

\section{Experimental Methods}

Airlift fermenters with internal draft tubes were designed and fabricated using the important design parameters recommended by Ogbonna (2013). Afterward, laboratory works following 
standard practices were carried out, oil spill and bioremediation processes were simulated and analysis of samples were done.

\section{(a) Design and Fabrication of Airlift Fermenter}

Airlift fermenters with total volumes of 7 and 70 litres respectively were designed and fabricated in the workshop of the Department of Chemical Engineering, Obafemi Awolowo University, Ile-Ife, using stainless steel material. Design parameters that were considered in the designing of the fermenters were the ratio of the diameter of the draft tube to the diameter of the vessel $\left(D_{L} / D_{T}\right)$ and the ratio of the diameter of the vessel to the height of the liquid column $\left(\mathrm{D}_{\mathrm{T}} / \mathrm{H}_{\mathrm{L}}\right)$. Ogbonna (2013) reported that $D_{\llcorner} / D_{T}$ and $D_{T} / H_{\llcorner}$should range from $0.6-0.8$ and $0.1-0.15$ respectively.

a) Height of liquid in reactor to height of reactor $\left(\mathrm{H}_{\mathrm{l}} / \mathrm{H}_{\mathrm{t}}\right)=0.7$

b) Height of tank to diameter of tank $\left(\mathrm{H}_{t} / \mathrm{D}_{\mathrm{t}}\right)=1$

They were standardized to appropriate working volumes of 5 and $50 \mathrm{~L}$ respectively and tested using aerated water.

(i) Dimensions for the 7 litres fermenter

The dimensions of the designed and fabricated 7 litres Airlift Fermenter are as given below:

a) For the External Tank:

$0.254 \mathrm{~m}$

Tank height, $\mathrm{h}_{\mathrm{T}}=10$ inches $=$

$0.196 \mathrm{~m}$

Tank diameter, $\mathrm{d}_{\mathrm{T}}=7.7$ inches $=$

b) For the Internal Tube:

Inner/central loop/tube diameter,
$\mathrm{d}_{\mathrm{L}}=3.08$ inches $=0.078 \mathrm{~m}$

$0.178 \mathrm{~m}$

$$
\text { Loop height, } h_{L}=7 \text { inches }=
$$

c) Distance from base of outer tank to base of central tube $=1.5$ inches $=0.038 \mathrm{~m}$

Figure 1 shows the design sketch of the 7 litres Airlift Fermenter.

(ii) Dimensions for the 70 litres fermenter The dimensions of the designed and fabricated 70 litres Airlift Fermenter are as given below:

a) For the External Tank:

$0.566 \mathrm{~m}$

Tank height, $\mathrm{H}_{\mathrm{T}}=22.3$ inches $=$ $0.406 \mathrm{~m}$

Tank diameter, $D_{\mathrm{T}}=16$ inches $=$

b) For the Internal Tube:

Inner/central loop/tube diameter, $D_{\llcorner}=6$ inches $=0.152 \mathrm{~m}$

Loop height, $\mathrm{H}_{\mathrm{L}}=15.59$ inches $=$ $0.396 \mathrm{~m}$

c) Distance from base of tank to base of central tube $=3$ inches $=0.076 \mathrm{~m}$

Figure 2 shows the design sketch of the 70 litres Airlift Fermenter.

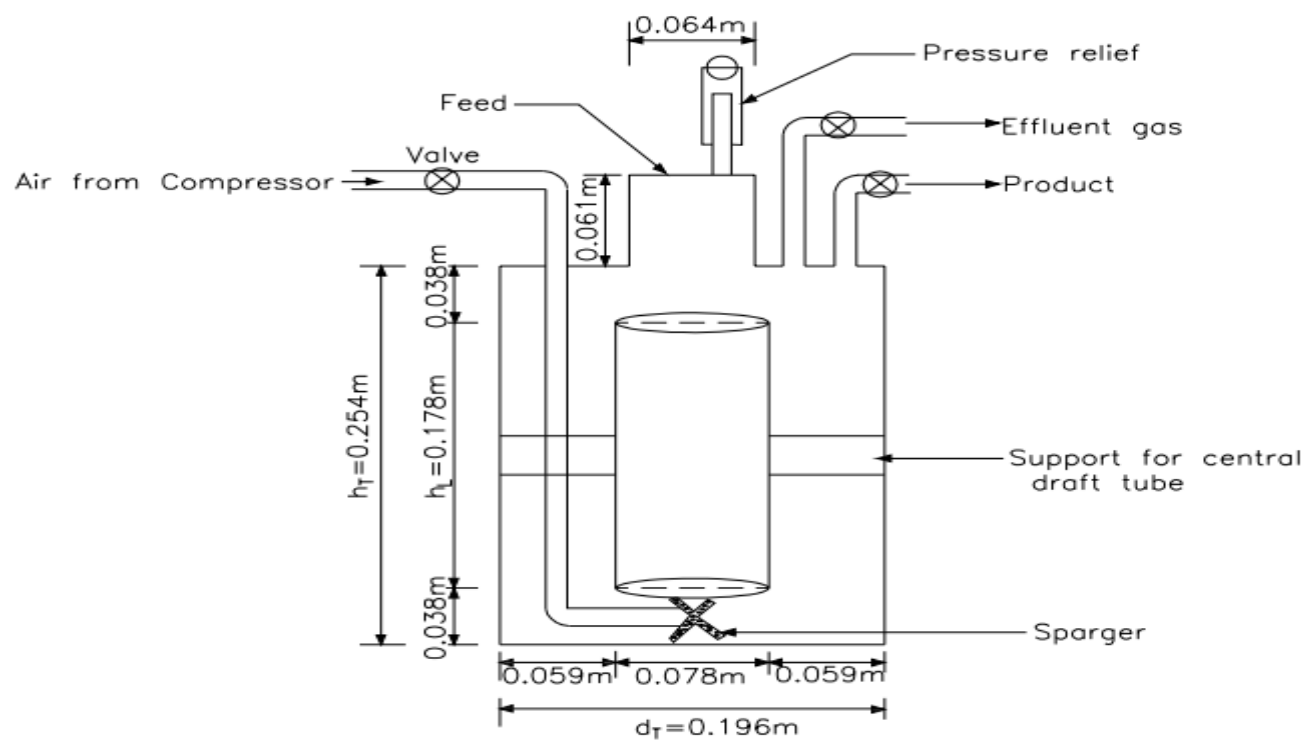


Figure 1: Design Sketch of the 7 litres Airlift Fermenter

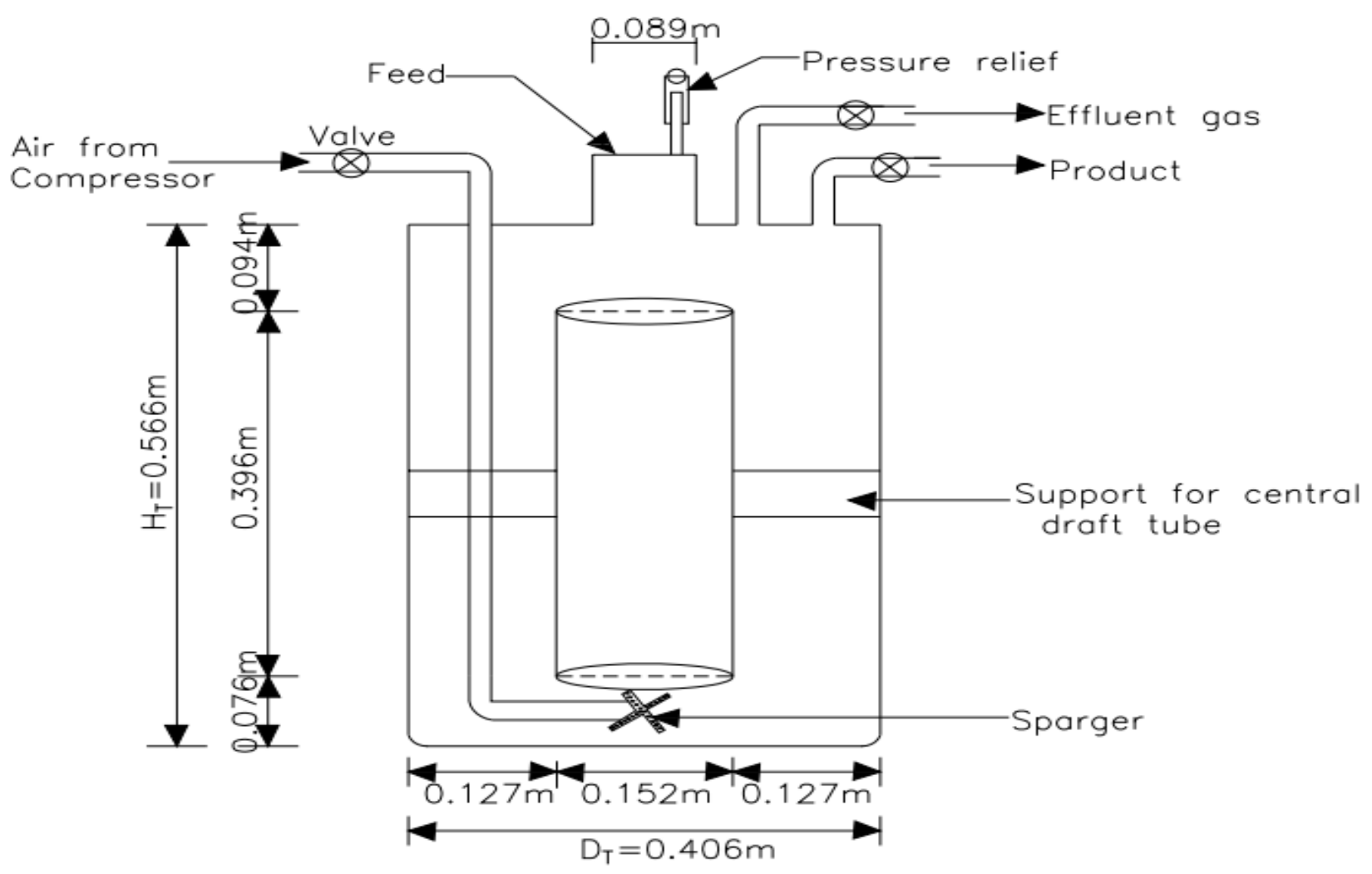

Figure 2: Design Sketch Used for Fabricating the 70 litres Airlift Fermenter

(b) Laboratory Works

(i) Agar Preparation and Inoculation of Microbes onto Agar Plates

For culturing the bacteria and fungus species, instructions on the manufacturer's manual were followed strictly in preparing the agar plates. Nutrient agar was prepared by dissolving $2.8 \mathrm{~g}$ of its powder in $100 \mathrm{ml}$ distilled water inside a $250 \mathrm{ml}$ conical flask. This was placed on a heater with stirrer to facilitate the dissolution of the nutrients. Sterilization of the contents of the flask was carried out in an autoclave at a temperature of $121^{\circ} \mathrm{C}$ and a pressure of 15 psi for 20 min. The flask was allowed to cool and its content was poured into petri dishes. This same procedure was followed for the preparation of malt extract agar except that $3.5 \mathrm{~g}$ malt extract agar powder was dissolved in $\mathbf{5 0}$ $\mathrm{ml}$ distilled water inside a $250 \mathrm{ml}$ conical flask. The three microbes: $P$. aeruginosa, $P$. fluorescence, and $A$. pullulans were inoculated from stock cultures into appropriate agar plates which were incubated at $38{ }^{\circ} \mathrm{C}$ for $48 \mathrm{~h}$ in order for sufficient growth to take place after which they were removed and stored in a refrigerator at $4 \pm 1^{\circ} \mathrm{C}$ until further use.

\section{(ii) Preparation of the Mineral Salt Water/Medium (Culture Medium) and the Inoculum}

The mineral salt water/medium was prepared according to the method described by Agarry et al. 
(2009). Two loops full of microbes were transferred from agar plates into $100 \mathrm{ml}$ of culture medium containing $90 \mathrm{ml}$ of mineral salt water and $10 \mathrm{ml}$ of crude oil. This was done in three shake flasks to cater for the three microbes. Duplicates of each were made and labelled. The duplicates served as sources for sampling and the essence was to leave the cultures, being studied, undisturbed. All six shake flasks were incubated in a New Brunswick incubator gyratory shaker for 48 $\mathrm{h}$ at $30{ }^{\circ} \mathrm{C}$ and agitated at a speed of $120 \mathrm{rpm}$. These were the primary microbial cultures. Samples were obtained for analysis every $12 \mathrm{~h}$, i.e., $0,12,24,36$ and 48 h. After observation for growth, $10 \mathrm{ml}$ of each of the three primary cultures were transferred in duplicates into $90 \mathrm{ml}$ of culture medium containing $80 \mathrm{ml}$ of mineral salt water and $10 \mathrm{ml}$ of crude oil. These new set of shake flasks were incubated for $48 \mathrm{~h}$ as previously described. These served as the secondary microbial cultures which were pooled together and from which 500 $\mathrm{ml}$ was taken as inoculum for the 7 litres fermenter.

(iii) Mass Propagation in the 7 litres Fermenter According to Ogbonna (2013), the fabricated fermenters were both used in mass producing the microbes. The 7 litres fermenter was used to mass propagate the consortium of microbes at 1 volume of air to volume of broth per minute (v.v.m) with the aid of an air compressor. Equal volumes of the grown organisms totaling an aggregate of $500 \mathrm{ml}$ of mixed culture were used to inoculate the sterile 4.5 litres culture medium contained in the 7 litres airlift fermenter. Fermentation runs were achieved at 1 volume of air per volume of liquid per minute (vvm) using an air compressor. Samples were withdrawn at $12 \mathrm{~h}$ intervals and analytical procedures were carried out on them. Thereafter, the secondary culture was used as inoculum for the 70 litres airlift fermenter. Plate 1 shows the 7 litres fermenter setup in operation. (iv) Mass Propagation in the 70 litres Fermenter Ten percent $(10 \%)$ of the secondary culture was transferred as inoculum into 45 litres medium in the 70 litres fermenter and was aerated at $3 \mathrm{vvm}$ using an air compressor which supplied air at a pressure of $98 \mathrm{kPa}$ or $14.2 \mathrm{psi}$ for the duration of fermentation time. The $\mathrm{pH}$ of the fermentation broth was maintained at a value of 6.9 using a buffer solution. The temperature of the fermentation broth was $36{ }^{\circ} \mathrm{C}$ on the average. Samples of culture broth were withdrawn at regular intervals for biomass determination and residual hydrocarbon analysis. The products of fermentation were introduced into the simulated polluted environment (water system).

\section{(c) Field Studies}

(i) Simulated Oil Spill and Bioremediation Process The water was carefully quantified and kept in containers. Ten (10) bowls were used for accommodating the Opa fresh river water. The volume of water in each bowl was 6 litres. On the basis of the ratio 1:10 for crude oil pollution of appreciable magnitude, 0.6 litres of crude oil was the quantity used for 6 litres of water. The simulated environment was polluted for a period of about 3 weeks and 4 days before the bioremediation process began. The mass propagated microbes were introduced into the polluted environment. Biostimulants were used alongside the microbes in a variable manner. The simulated crude oil polluted environmental setup is as shown on Plate 2. Each of the water samples were stirred twice weekly to aid aeration and create the enabling conditions for the microbes to biodegrade the hydrocarbons.

(d) Analytical Procedures

Samples withdrawn from the fermenters and obtained from the water setup were subjected to several analytical methods in order to monitor the progress of the bioremediation process. 


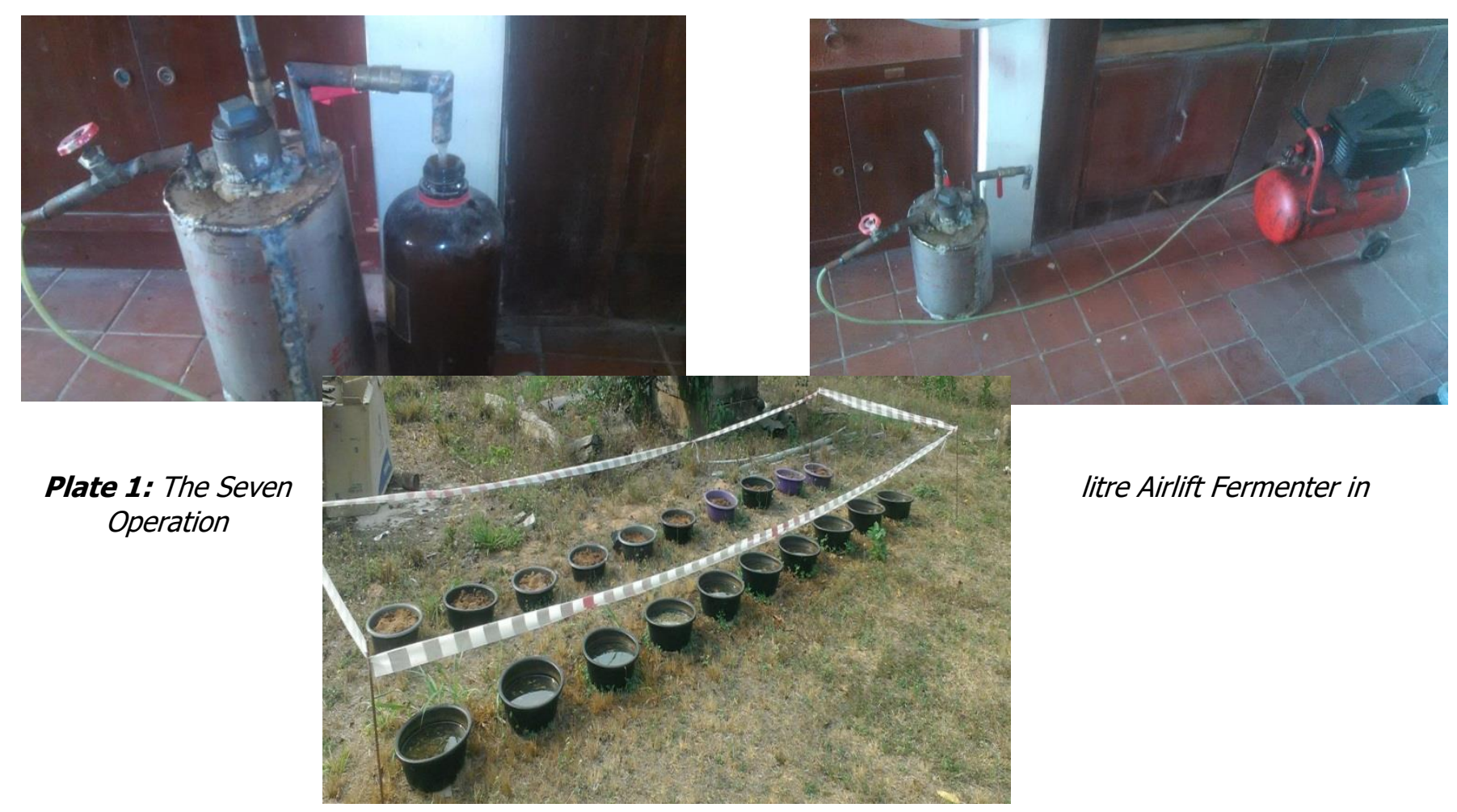

Plate 2: Simulated Crude Oil Polluted Water Environment (Right hand side)

Water samples:

Wa $=$ Crude oil alone (control)

$\mathrm{Wb}=$ Crude oil + microorganisms

Wc $=$ Crude oil + urea

Wd $=$ Crude oil + urea + microorganisms

We $=$ Crude oil + NPK

Wf = Crude oil + NPK + microorganisms

Wg $=$ Crude oil + cow dung

Wh $=$ Crude oil + cow dung + microorganisms

Wi $=$ Crude oil + poultry droppings

$\mathrm{Wj}=$ Crude oil + poultry droppings + microorganisms (i) Cell biomass concentration measurement The cell biomass concentrations of the water samples from the fermenters were determined via the dry weight method (Agarry and Solomon, 2008). A sheet of cellulose acetate filter membrane was weighed and stored in a desiccator lined with anhydrous $\mathrm{CaSO}_{4}$. The flask was stirred to suspend the culture evenly; $100 \mathrm{ml}$ of the culture was poured into a graduated cylinder. The cells were separated from the broth by centrifugation at $5,000 \mathrm{rpm}$ for $5 \mathrm{~min}$, after which the clear broth was decanted into an empty container and the cell paste was scraped from the centrifuge tube into a sheet of filter paper. The centrifuge tube was rinsed with a few $\mathrm{ml}$ of distilled water and its content was poured onto the filter paper and dried at $105^{\circ} \mathrm{C}$ to final constant dry weight.

(ii) Residual hydrocarbon determination

Crude oil standard was prepared by pipetting 1.18 $\mathrm{ml}$ of crude oil into a $1000 \mathrm{ml}$ standard flask and the volume was made up to the mark with n- 
hexane to obtain a $1000 \mathrm{ppm}$ concentration. From the standard, concentrations of 100,80,60, 40, 20, and $10 \mathrm{ppm}$ crude oil were prepared. The optical densities of these prepared solutions were determined using a visible Spectrophotometer operated at a wavelength of $540 \mathrm{~nm}$ and a standard curve for hydrocarbon concentration against optical density was obtained.

Water samples withdrawn at regular intervals from the fermenters (12-hourly) and the simulated environmental systems (weekly) were subjected to analysis. Ten (10) $\mathrm{ml}$ of $\mathrm{n}$-hexane was poured into $50 \mathrm{ml}$ of the withdrawn water samples and the mixture was shaken for $30 \mathrm{~s}$ and allowed to stand for $20 \mathrm{~min}$. After this, it was shaken for another 10 min and then filtered. Twenty-five (25) $\mathrm{ml}$ of the samples were then poured into volumetric flasks and their optical densities were determined using the visible Spectrophotometer operated under the same conditions. These densities were then compared against the standard curve and the residual hydrocarbon of the samples were determined.

\section{Results and Discussions}

Efficiency of the Designed 7 and 70 Litres

Fermenters

The efficiency of these designed fermenters were tested via mass propagation of the microorganisms. The 7 I fermenter was used in the mass propagation of the consortium of microorganisms and the results were presented in Figure 3. At an initial cultivation time of $0 \mathrm{~h}$, the cell concentration was determined to be $0.25 \mathrm{~g} / \mathrm{l}$ while the hydrocarbon concentration in the culture broth was noted to be $464.5 \mathrm{~g} / \mathrm{l}$. A constant growth rate was observed after the cells were well adapted; the cells grew rapidly until the logarithmic (exponential) growth phase was attained. After the entire period of mass propagation in which the $\mathrm{pH}$ was maintained at a value of 6.9 and a temperature of $38{ }^{\circ} \mathrm{C}$, the hydrocarbon concentration was observed to drop by $78.5 \%$ from $464.5 \mathrm{~g} / \mathrm{l}$ to $105.9 \mathrm{~g} / \mathrm{l}$. This showed that there was reasonable level of activity of the consortium consisting of Pseudomonas aeruginosa, $P$. fluorescence and $A$. pullulans on the substrate. This is in accordance with the reports given by Agarry et al. (2010) when a binary mixture of the first two organisms was used to degrade phenol.

From the 70 litres fermenter as shown in Figure 4, immediate growth was observed (no lag) initially at time $0 \mathrm{~h}$ with a cell concentration of $2.08 \mathrm{~g} / \mathrm{l}$ which appreciated within the first $12 \mathrm{~h}$ to a cell concentration of $2.89 \mathrm{~g} / \mathrm{l}$. The reason for this lies in the fact that cells were transferred to a freshly formulated medium having all the required nutrients in adequate proportions. Another reason is that the inoculum obtained from the 7 । fermenter was taken out at the log/exponential phase; this is very important because if the organism used as inoculum is at the log phase, there will be no lag (Solomon, 2001). The initial concentration of crude oil was analyzed and found out to be $464.5 \mathrm{~g} / \mathrm{l}$ which reduced significantly to $393.5 \mathrm{~g} / \mathrm{l}$ and was quantified as $15 \%$ hydrocarbon reduction in the first $12 \mathrm{~h}$ of mass propagation in the airlift fermenter. In the process of time, the cell mass accelerated from 2.89 to $3.125 \mathrm{~g} / \mathrm{l}$ in 24 $\mathrm{h}$ with corresponding decrease in hydrocarbon concentration from 393.5 to $320.9 \mathrm{~g} / \mathrm{l}(30.9 \%$ reduction) within the same time range. The log/exponential phase had a constant biomass growth as observed in the gradual increase in cell concentration from $3.125 \mathrm{~g} / \mathrm{l}$ to $10.8 \mathrm{~g} / \mathrm{l}$, while hydrocarbon concentration diminished from 320.9 to $198.7 \mathrm{~g} / \mathrm{l}$ (57\% reduction) in $36 \mathrm{~h}$.

The cells were under growth limited condition from the 60th hour onwards. This decline in growth may be due to substrate limitation (i.e., substrate concentration is lower than the saturation constant), or may be due to depletion of other nutrients in the medium. Other probable limitations are physical and chemical conditions in the medium such as the culture broth viscosity or high concentrations of inhibitory products and byproducts. After a duration of $180 \mathrm{~h}$ of mass propagation using the 70 | fermenter, $97.8 \%$ reduction in hydrocarbon concentration was achieved. This indicates that the fermenter was very efficient in making adequate microbial population available for bioremediation of simulated crude oil polluted land and water systems. In addition, the occurrence of foaming in an airlift fermenter/bioreactor is due to the diameter and the top of the vessel being the same as stated by Paek et al. (2005). This problem of foaming was overcome by ensuring that the 70 I airlift fermenter was designed with a larger height to diameter ratio. The performance of the mass propagation process was better at $3 \mathrm{vvm}(97.8 \%$ hydrocarbon removal) as against $1 \mathrm{vvm}(78.5 \%$ hydrocarbon removal) earlier used. 
Ejianreh et al. / Nig. J. Biotech. Vol. 36 Num. 2 : 95 - 113 (December 2019)

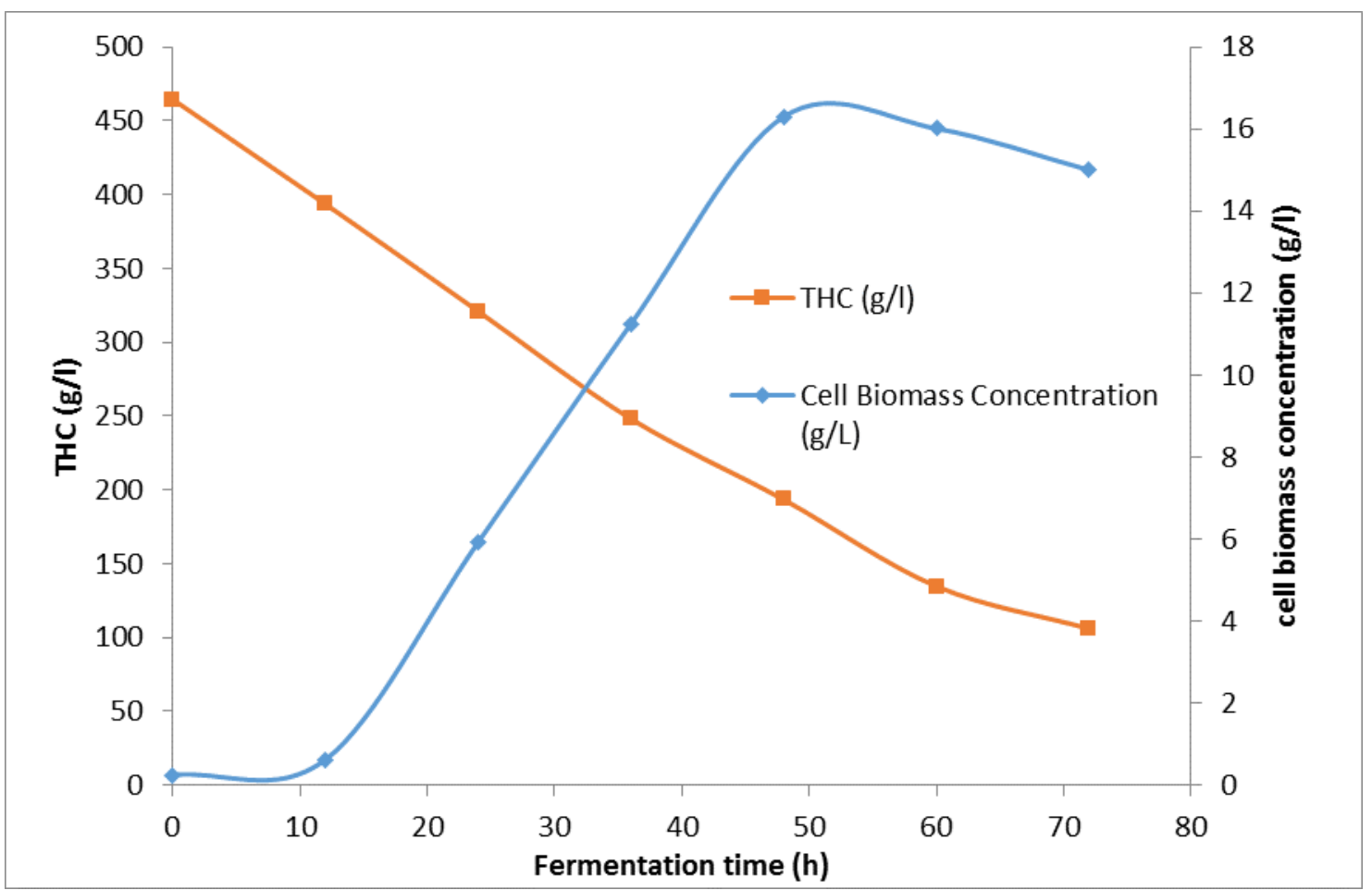

Figure 3: Variation of Cell Growth and Residual Hydrocarbon concentration against time for $7 /$ fermenter

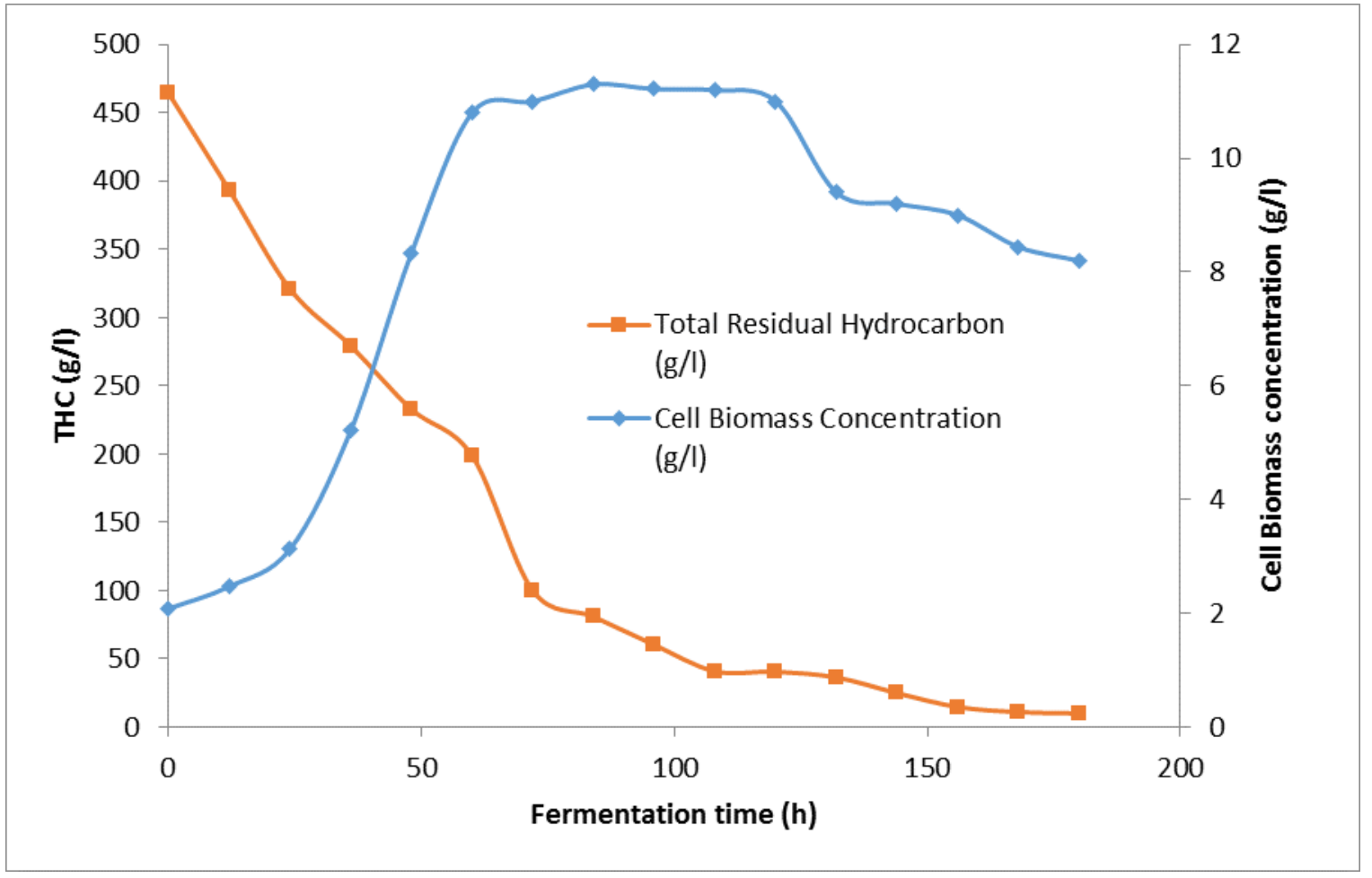

Figure 4: Variation of Cell Growth and Residual Hydrocarbon concentration 70 / fermenter 
Ejianreh et al. / Nig. J. Biotech. Vol. 36 Num. 2 : 95 - 113 (December 2019) 


\section{Residual Hydrocarbon Determination}

Pseudomonas and Aureobasidium species were cultured separately in conical flasks. The batch culture studies revealed that $P$. aeruginosa (Figure 5 ) degraded the hydrocarbons present by $89.6 \%$ after a period of $48 \mathrm{~h}$. An observation of the flask showed a transformation in colour from initial deep reddish brown to tinted yellow after $48 \mathrm{~h}$ of fermentation. Similar results were obtained when $P$. fluorescence (Figure 6) was cultured. These microbial species showed higher hydrocarbon degrading ability than the aforementioned species as seen in previous studies (Agarry and Solomon, 2008).

A. pullulans, a fungus which had shown good prospects in bioremediation of textile dye solutions and mixtures as well as textile effluents (Ademakinwa and Agboola, 2015) successfully degraded hydrocarbons. Though, it had not been previously reported that it could degrade crude oil polluted environments. It was observed that after $48 \mathrm{~h}$ of cultivation, there was a colour change from deep reddish brown to pale yellow (Plate 3 ) and 88 $\%$ reduction in hydrocarbon concentration was achieved (Figure 7). After $72 \mathrm{~h}$ of fermentation (Figure 8), a reasonable level of microbial degrading activity was observed due to $78.5 \%$ reduction in hydrocarbon concentration. This is similar to the study done by Agarry et al. (2010) when a binary mixture of two Pseudomonas species was used to degrade phenol. After $180 \mathrm{~h}$ of mass propagation using the 70 litres fermenter (Figure 9), $97.8 \%$ reduction in hydrocarbon concentration was achieved.

The blend consortium of microbes was applied on the polluted water samples. The varying results are given in Figures 10,11,12, 13 and 14. It is worthy to note that few days after the simulated pollution was carried out, dead animals/insects such as toad/flies were found on polluted water [Plate 4(a)]. However, after 97 days of treatment (bioremediation), tadpoles were seen swimming and multiplying in numbers [Plate 4(b)].

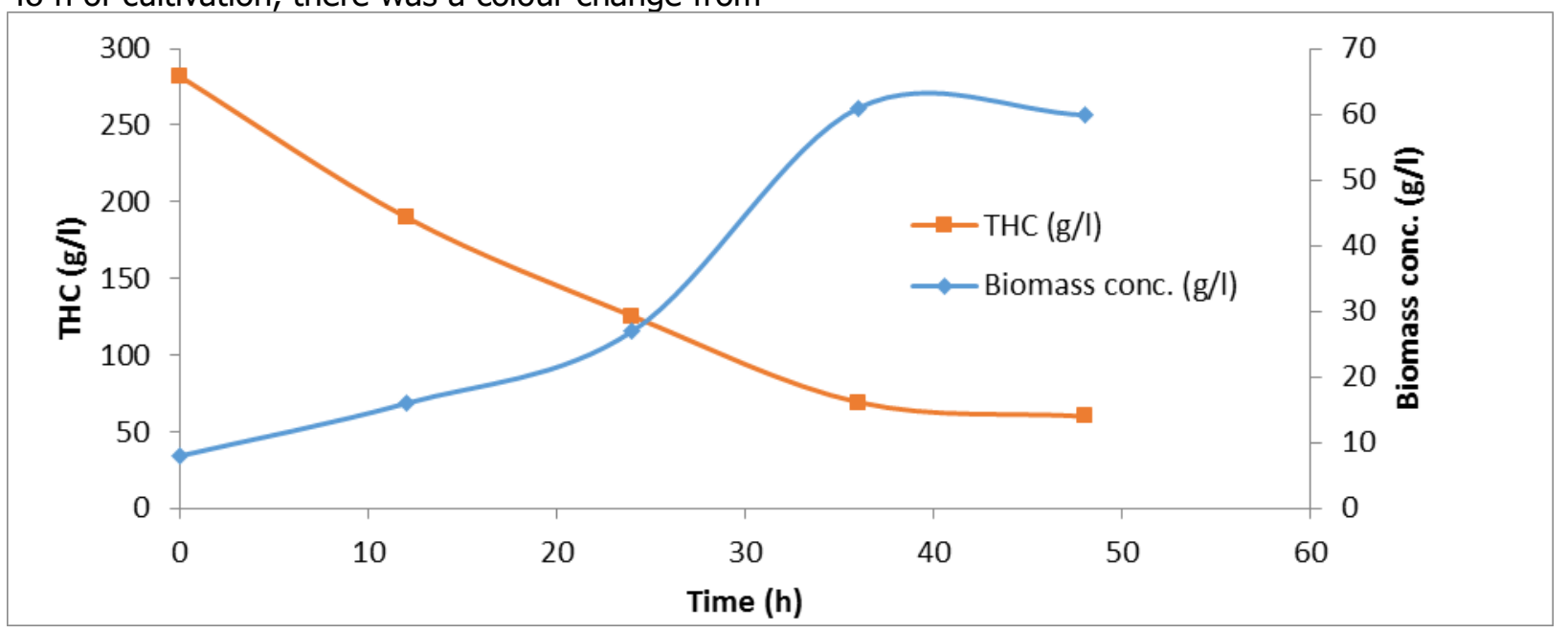

Figure 5: Variation of Cell Growth and Residual Hydrocarbon concentration against time for Pseudomonas aeruginosa 
Ejianreh et al. / Nig. J. Biotech. Vol. 36 Num. 2 : 95 - 113 (December 2019)

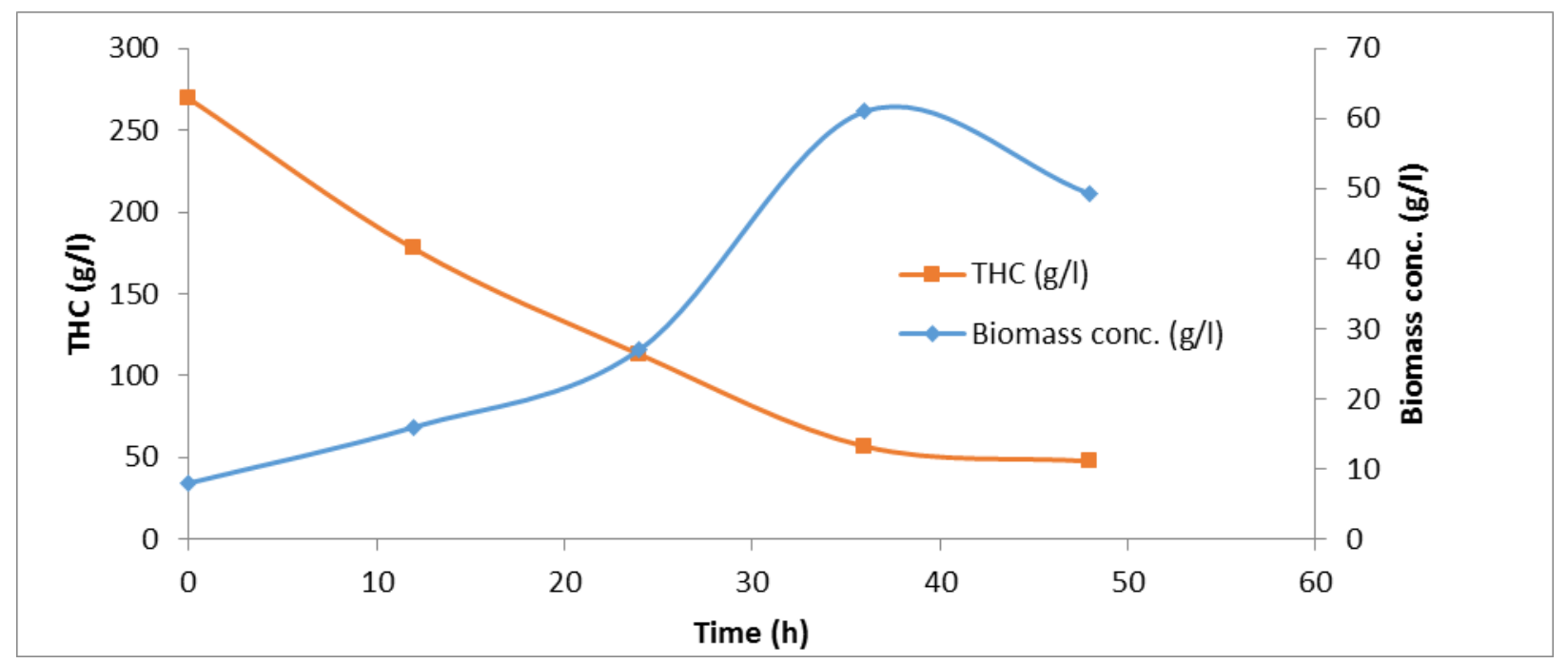

Figure 6: Variation of Cell Growth and Residual Hydrocarbon concentration against time for Pseudomonas fluorescence

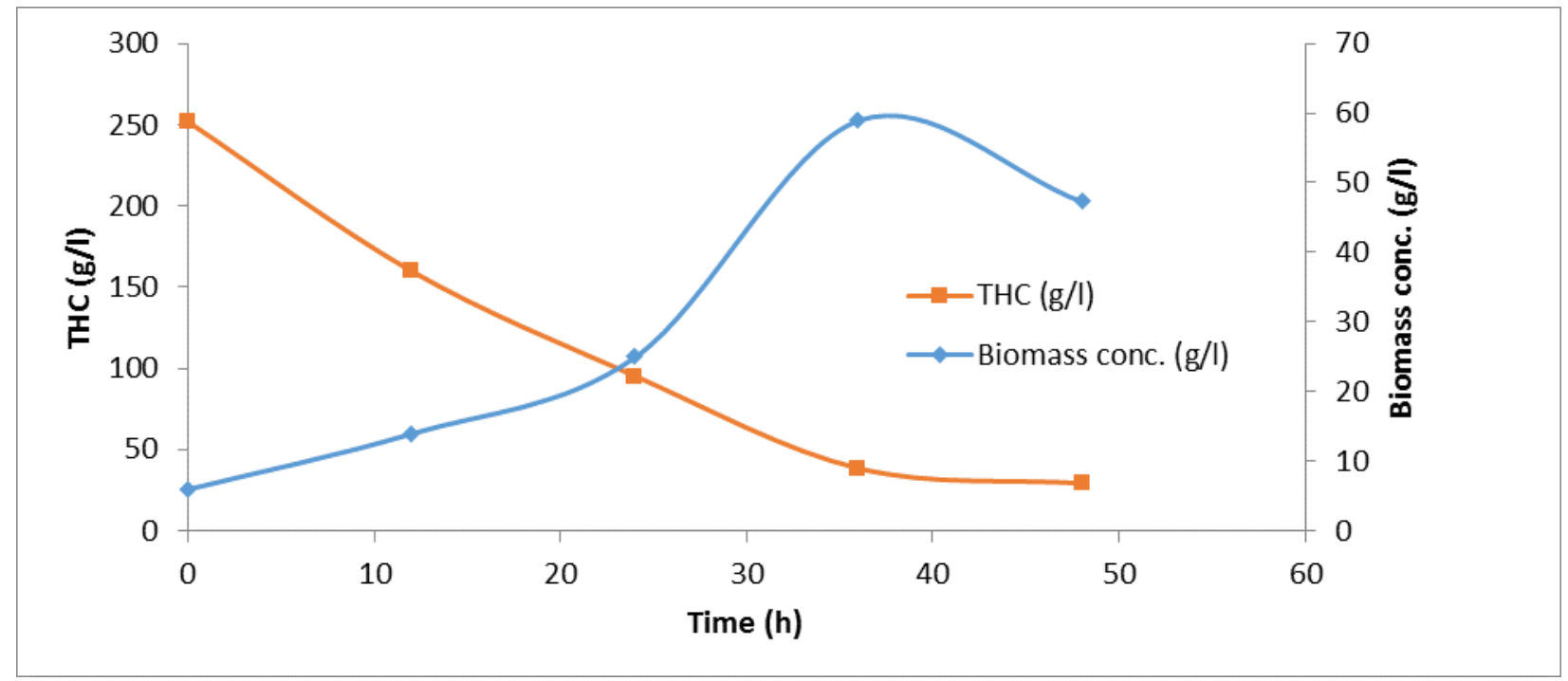

Figure 7: Variation of Cell Growth and Residual Hydrocarbon concentration against time for Aureobasidium pullulans 
Ejianreh et al. / Nig. J. Biotech. Vol. 36 Num. 2 : 95 - 113 (December 2019)

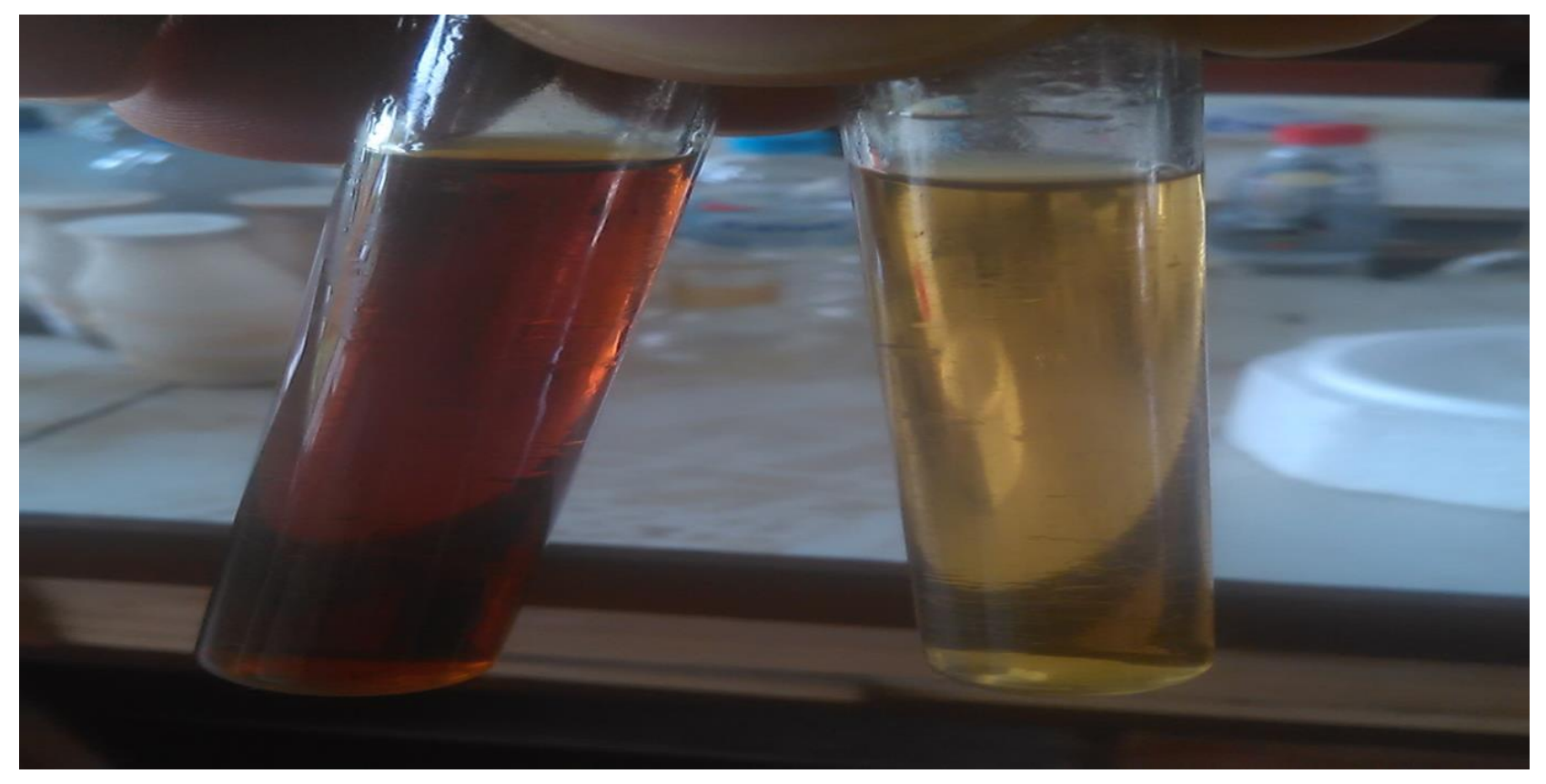

Plate 3: Substrate Colour Variation; Deep Reddish Brown (Left) and Golden Yellow (Right) 
Ejianreh et al. / Nig. J. Biotech. Vol. 36 Num. 2 : 95 - 113 (December 2019)

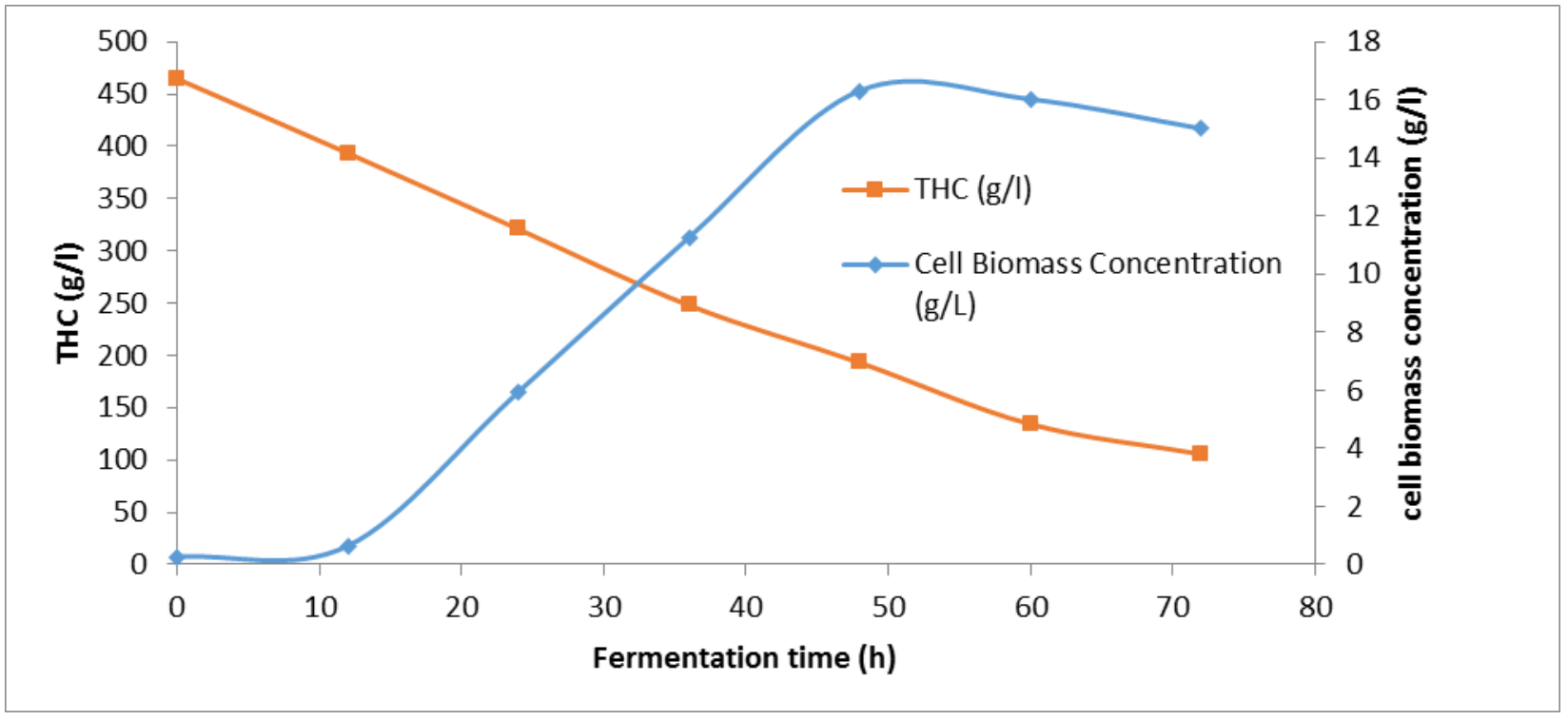

Figure 8: Variation of Cell Growth and Residual Hydrocarbon concentration against time for 7 litres fermenter

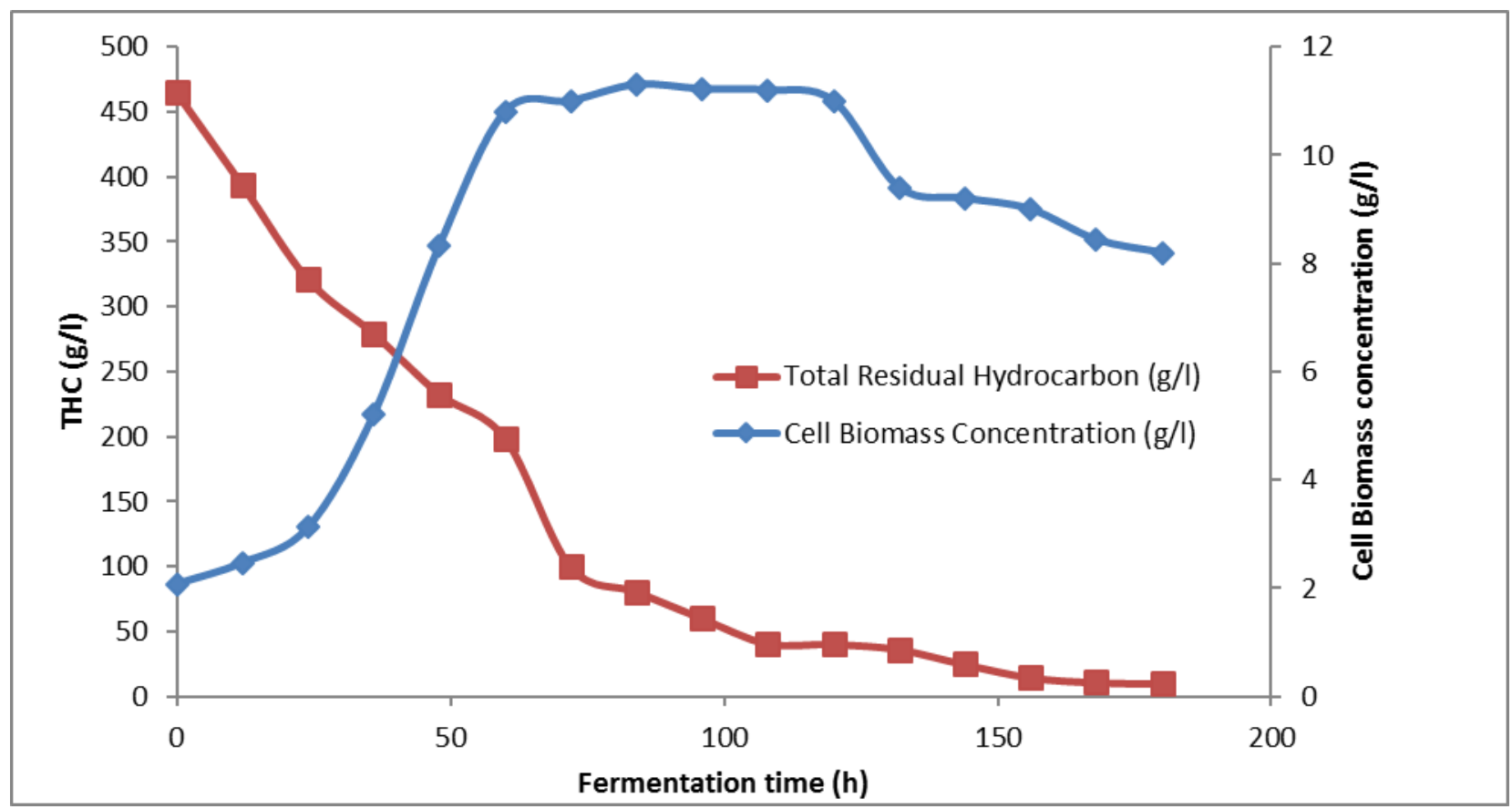

Figure 9: Variation of Cell Growth and Residual Hydrocarbon concentration against time for 70 litres fermenter 


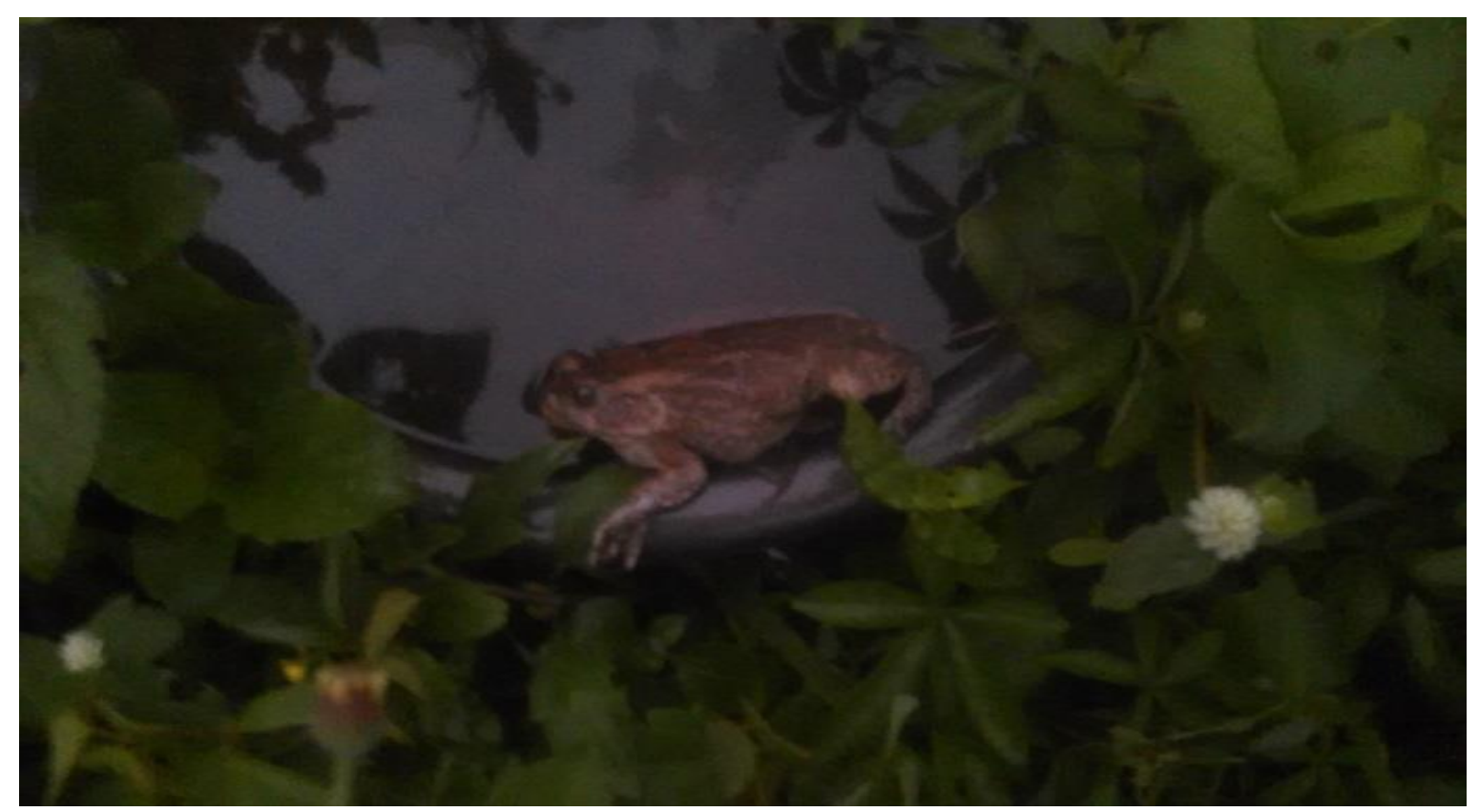

Plate 4(a): After pollution with crude oil or before bioaugmentation and biostimulation (lifeless toad)

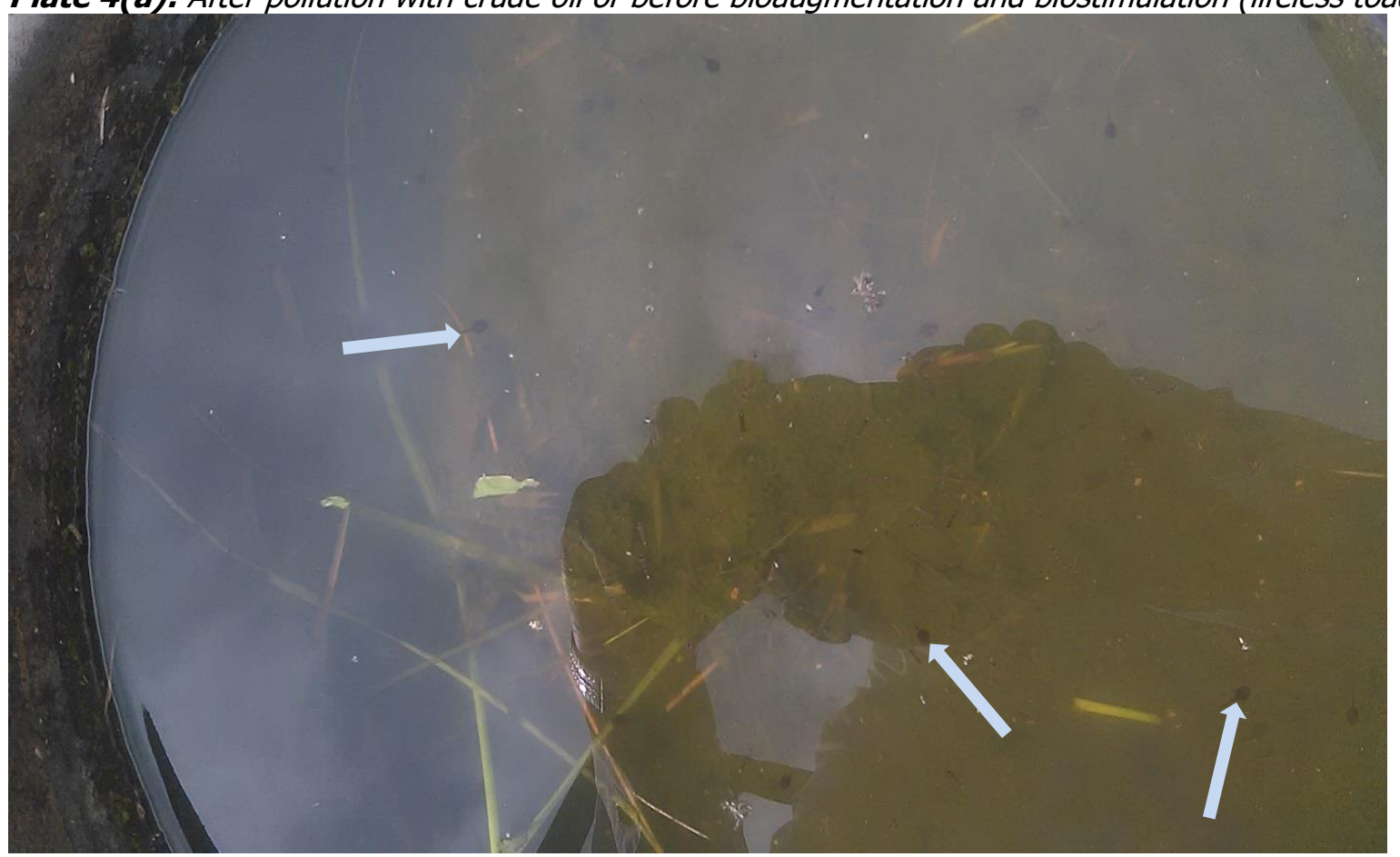

Plate 4(b): Colored arrows showing moving tadpoles after 97 days of bioremediation

The performance of the microbes as a consortium in the batch airlift fermenters follows the normal cell growth curve, and substrate consumption corresponds proportionally to each stage of growth of the cells. However, the rate of growth in each airlift fermenter was different; in addition, substrate consumption (hydrocarbon degradation) was also not the same. This was due to difference in aeration rates in each airlift fermenter. These aeration rates (Luttmann et al., 1982) accounted for the percentage crude oil removal in both fermenters irrespective of the working volumes in both of them. The 7 litres airlift fermenter was operated at 1 v.v.m with hydrocarbon removal of $78.5 \%$ achieved, hence the rate of agitation of fermentation broth was not as effective/vigorous as that of the 70 litres fermenter which was operated at 
3 v.v.m with an achieved hydrocarbon removal of $97.8 \%$. This precaution was taken in order to preserve the fragile cells (Martin et al., 2004) since they were in the 7 litres for the sole aim of generating a mixed culture of bacteria and fungus. The 70 liters fermenter was the device used for the actual mass propagation of the consortium.

As shown in Figure 10, both water samples of $\mathrm{Wa}$ and $\mathrm{Wb}$ had an exchange of matter with their surroundings. Photo oxidation took place, environmental factors such as rainfall contributed to the general reduction in hydrocarbon degradation. However, the consortium of microbes had a great impact on the polluted environment in sample Wb. A critical look at the bar chart shows a difference between the two polluted samples. Bioremediation by bioaugmentation (Mishra et al., 2001) was much more impactful than natural bioremediation due to the existence of unidentified consortia of indigenous microbes acting in/on the untreated crude oil polluted sample. At the beginning of the bioremediation process (time zero), the total residual hydrocarbon concentration (THC) had not changed from its initial value of $300 \mathrm{~g} / \mathrm{l}$ in both samples.

Referring to Figure 11, sample Wc denotes the polluted water sample which was biostimulated using urea while sample $\mathrm{Wd}$ denotes the polluted water sample which was both biostimulated and bioaugmented using urea and the consortium of microbes respectively. Some fluctuations in the rate of biodegradation of crude oil pollutants were observed in the plot; the chart for sample Wc indicated that biodegradation was faster than that of sample Wd. However, between weeks 4 and 7, there was a brief swap such that sample Wd had a faster rate of biodegradation than sample Wc. It was also observed that between weeks 8 and 10, the rate of degradation was faster in sample Wc than in sample Wd. From the observations, it was inferred that the presence of a known quantity of urea alone in the crude oil polluted water sample containing a consortium of known microbes, inhibited the activities of the microbes such that their degrading abilities were slowed down. Other researchers who have reported the use of urea have not only used it alone but with other chemical stimulants. Amenaghawon et al. (2013) reported the effective use of urea and NPK $15: 15: 15$ fertilisers in stimulating the activity of microbes for bioremediation in wastewater. Likewise, Nikolopoulou et al. (2007) reported that the treatment of oil spills with uric acid and lecithin was very effective in a period of almost 7 days.

Sample We denotes the polluted water sample which was biostimulated using NPK while sample Wf denotes that which was both biostimulated and bioaugmented using NPK and the consortium of microbes respectively. The data obtained are presented in Figure 12. NPK fertilizer showed very good prospects in biostimulation and bioaugmentation. It also aided the degradation rate of the hydrocarbons when combined with the microbes. For most of the study times, sample Wf had a faster degradation rate on the average than that of sample We. In a nutshell, the biostimulant did not inhibit but aided the microbial activity in the bioremediation process. This is in line with the study carried out by Nwankwegu et al. (2016). From Figure 13, sample Wh had a much slower degradation rate than sample Wg. Sample Wg contained some quantity of cow dung as its biostimulant while sample Wh contained both cow dung and microorganisms. It was inferred that cow dung had an inhibitory effect on the microbes. The hydrocarbon concentration left after 10 weeks was $15.3 \mathrm{~g} / \mathrm{l}$ in $\mathrm{Wg}$ and $28 \mathrm{~g} / \mathrm{l}$ in Wh. A very similar trend was obtained in samples Wi and Wj. Sample Wi contained only the biostimulant, poultry droppings while sample $\mathrm{Wj}$ contained both biostimulant and the microbes which were used for bioaugmentation. The data obtained are presented in plotted in Figure 14. Poultry droppings when used as biostimulants were more effective in biodegradation than when combined with microbes. It is inferred from this study that it is better to combine the biostimulant with chemical stimulants as suggested for Wc and Wd samples. However, the quantity used could be varied to identify optimal levels of action in a bioremediation process. 
Ejianreh et al. / Nig. J. Biotech. Vol. 36 Num. 2 : 95 - 113 (December 2019)

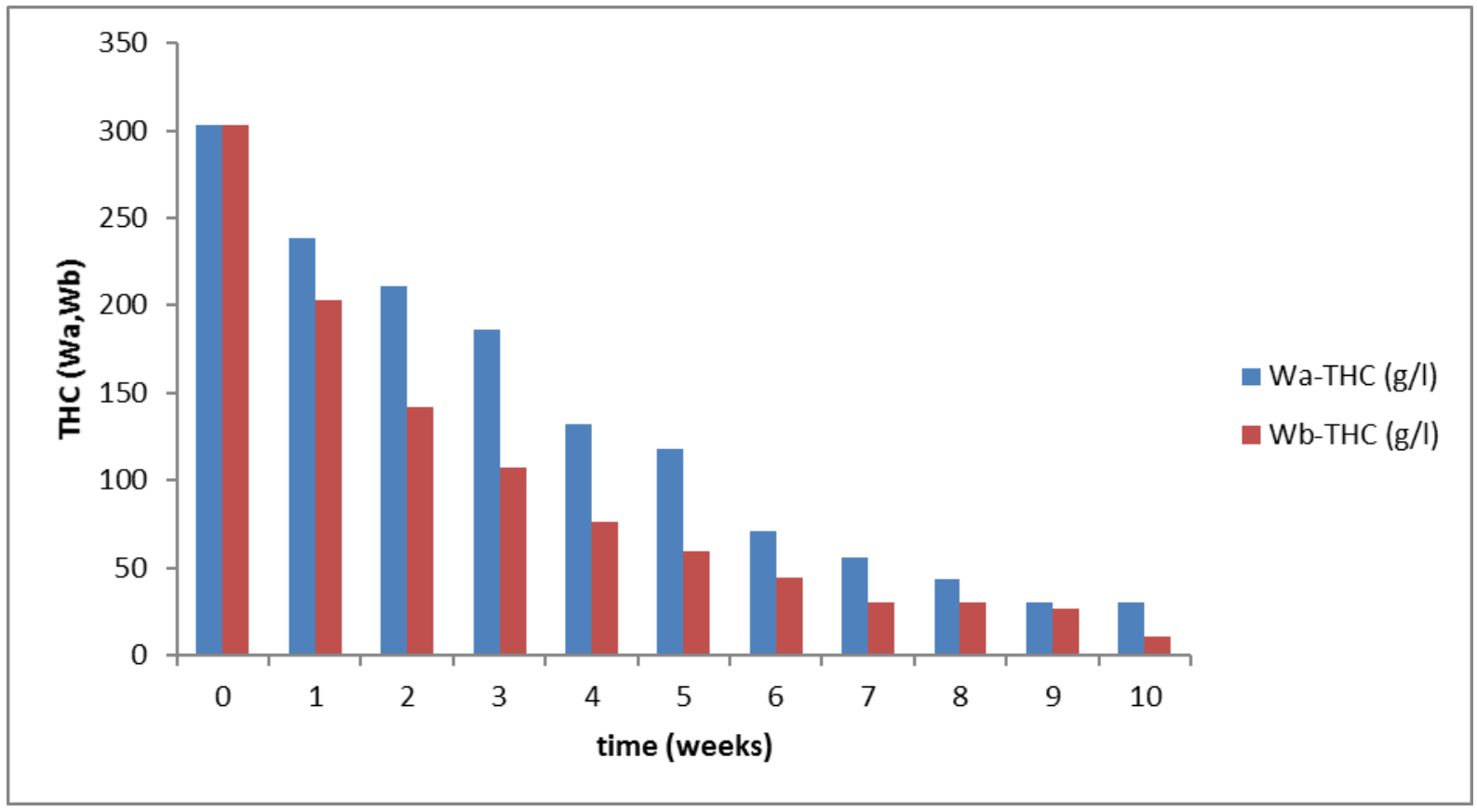

Figure 10: Comparing THC in Water Samples Wa and Wb

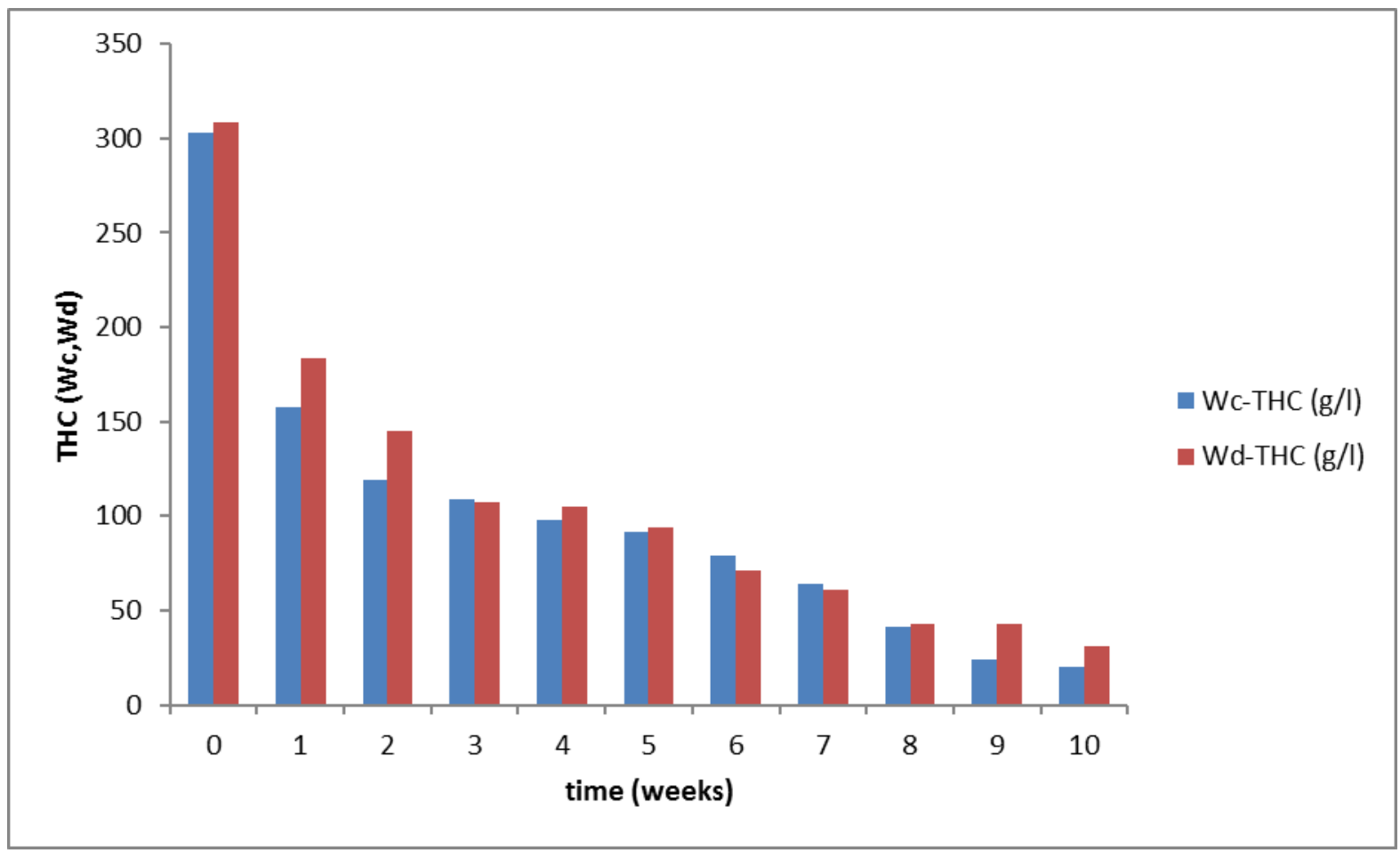

Figure 11: Comparing THC in Water Samples Wc and Wd 
Ejianreh et al. / Nig. J. Biotech. Vol. 36 Num. 2 : 95 - 113 (December 2019)

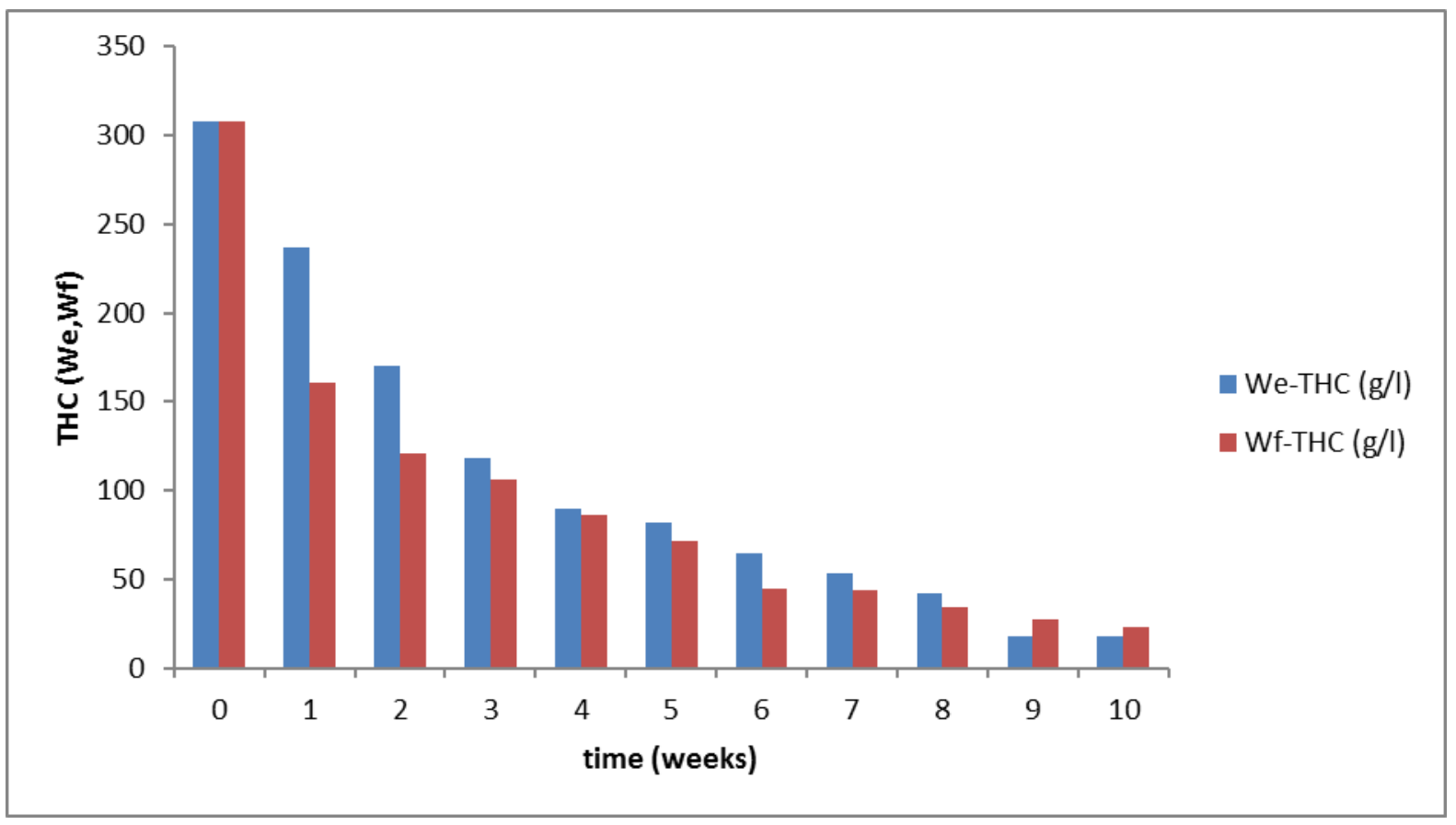

Figure 12: Comparing THC in Water Samples We and Wf

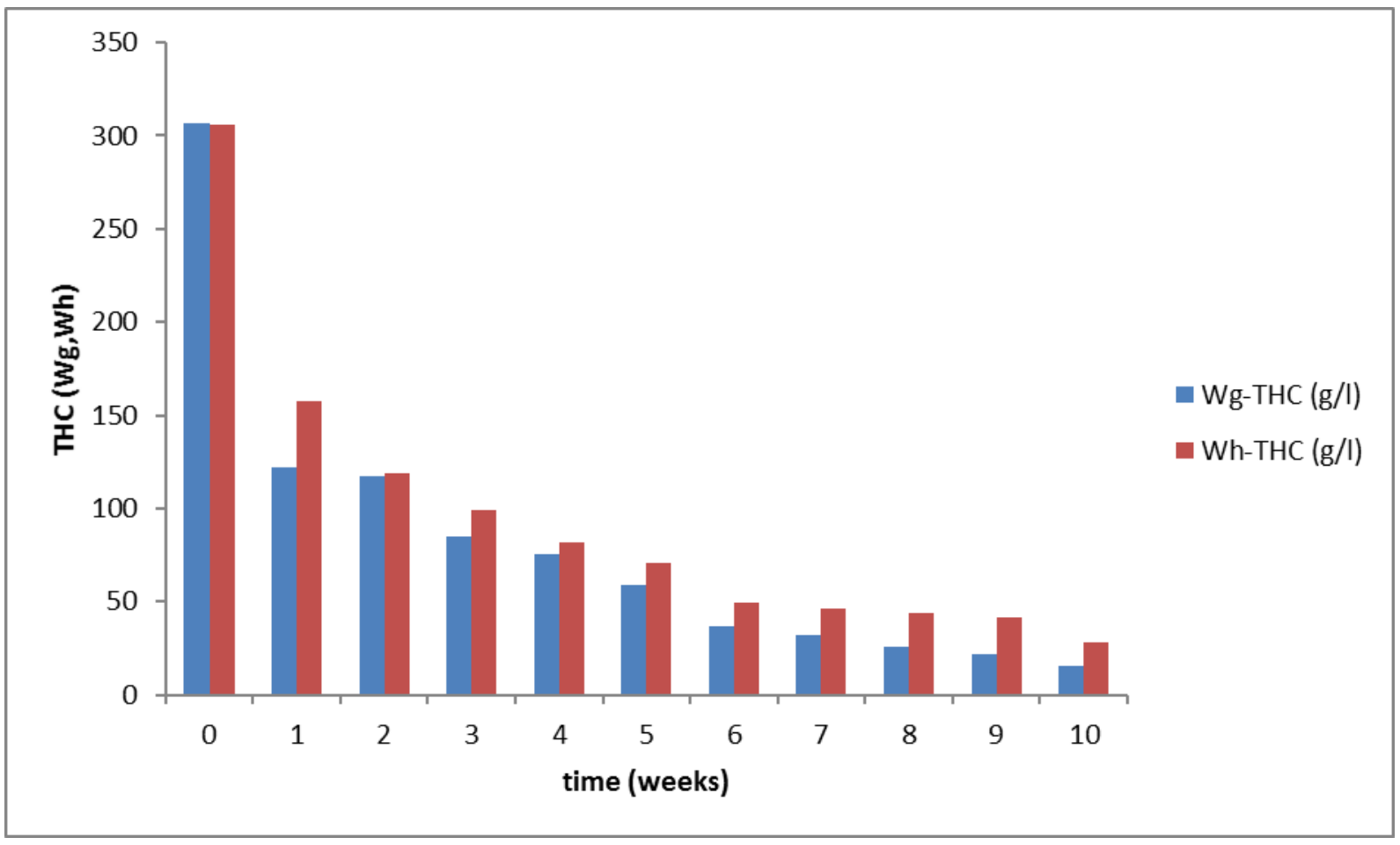

Figure 13: Comparing THC in Water Samples Wg and Wh 


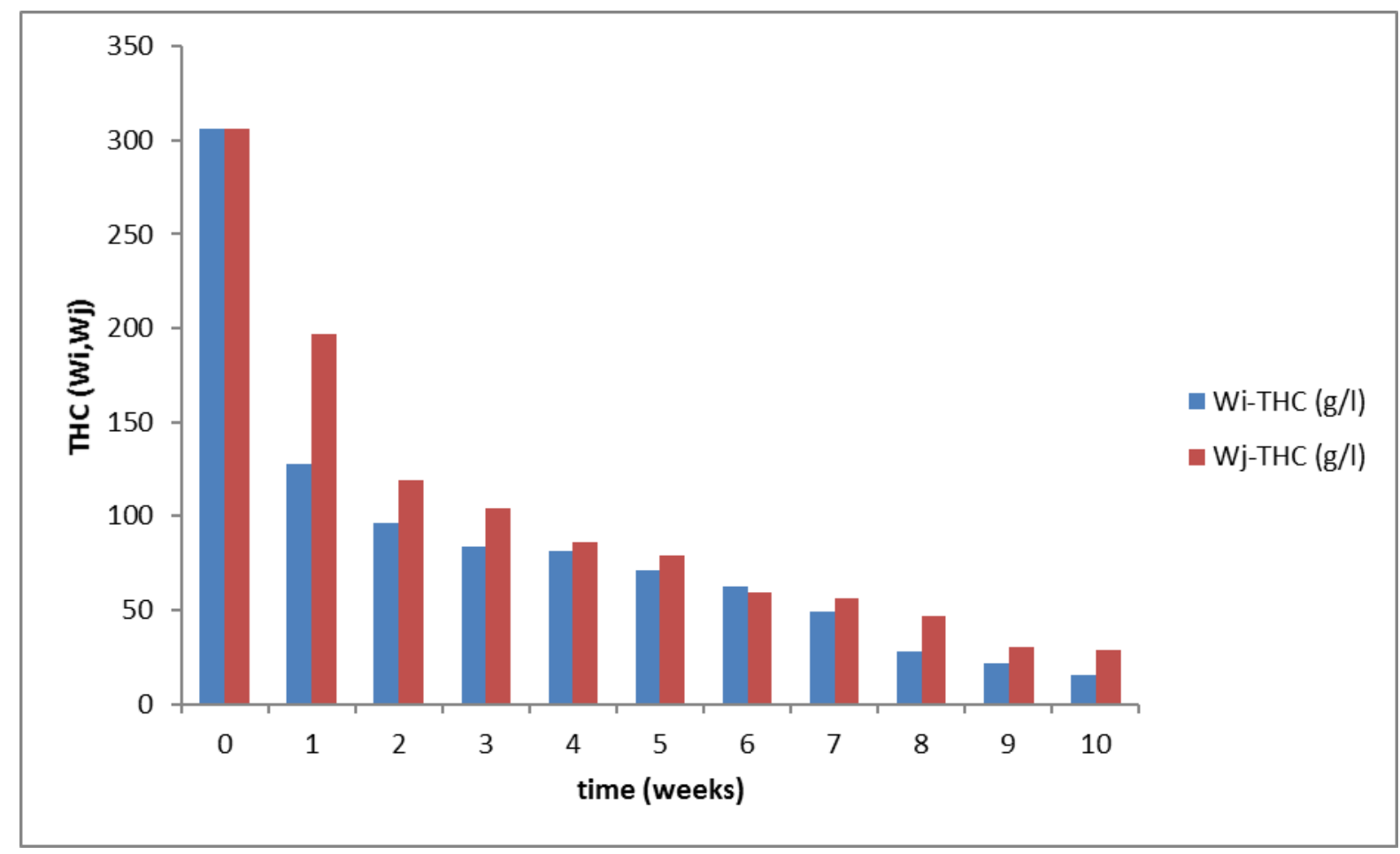

Figure 14: Comparing THC in Water Samples Wi and Wj

\section{Conclusion}

Pseudomonas aeruginosa, P. fluorescence, and Aureobasidium pullulans showed good response to the hydrocarbon substrate and were resistant to the toxicity of crude oil; the fabricated 7 and 70 litres airlift fermenters utilized in this study proved to be highly effective and very efficient in the mass propagation of Pseudomonas and Aureobasidium species, and the products formed from this bioprocess had a significant impact on crude oil polluted aquatic environments. It was observed that there was $78.5 \%$ removal of hydrocarbon contaminants in the 7 litres fermenter, while there was 97.8 $\%$ removal of petroleum hydrocarbons in the 70 litres fermenter at the end of the fermentation studies. This study provided adequate and useful information on effective bioremediation of crude oil polluted water systems through mass propagation of isolated crude oil degrading microorganisms with the aid of airlift fermenters. This research work provides a contribution to the efforts made by the Federal Government of Nigeria to clean up Ogoni land and it is possible to reduce its duration from the estimated 30 years to a reasonable duration of time if methods and techniques adopted from this study are applied on an industrial scale.

\section{References}

Ademakinwa, A. N. \& Agboola, F. K. (2015). Bioremediation Of Textile Dye Solutions, Textile Dye Mixtures And Textile Effluents By Laccase From Aureobasidium Pullulans (De Bary) G. Arnaud (1918)(Fungi: Ascomycota). Brazilian Journal Of Biological Sciences, 2, 253-262.

Agarry, S., Audu, T. \& Solomon, B. (2009). Substrate Inhibition Kinetics Of Phenol Degradation By Pseudomonas Fluorescence From Steady State And Wash-Out Data. International Journal Of Environmental Science \& Technology, 6, 443-450.

Agarry, S. \& Solomon, B. (2008). Kinetics Of Batch Microbial Degradation Of Phenols By Indigenous Pseudomonas Fluorescence. International Journal Of Environmental Science \& Technology, 5, 223-232.

Agarry, S., Solomon, B. \& Audu, T. (2010). Substrate Utilization And Inhibition Kinetics: Batch Degradation Of Phenol By Indigenous Monoculture Of Pseudomonas Aeruginosa. International Journal Of Biotechnology And Molecular Biology Research, 1, 22-30. Amenaghawon, A. N., Asegame, P. A. \& Obahiagbon, K. O. (2013). Potential 
Application Of Urea And Npk 15: 15: 15

Fertilizers As Biostimulants In The

Bioremediation Of Domestic Wastewater.

American Journal Of Environmental Protection, $1,91-95$.

Atlas, R. M. (1981). Microbial Degradation Of Petroleum Hydrocarbons: An Environmental Perspective. Microbiological Reviews, 45, 180.

Atlas, R. M. \& Raymond, R. L. (1977).

Stimulated Petroleum Biodegradation. Crc Critical Reviews In Microbiology, 5, 371-386.

Balba, M., Al-Awadhi, N. \& Al-Daher, R. (1998). Bioremediation Of Oil-Contaminated Soil: Microbiological Methods For Feasibility Assessment And Field Evaluation. Journal Of Microbiological Methods, 32, 155-164.

Barathi, S. \& Vasudevan, N. (2001). Utilization Of Petroleum Hydrocarbons By Pseudomonas Fluorescens Isolated From A PetroleumContaminated Soil. Environment International, 26, 413-416.

Barathi, S. \& Vasudevan, N. (2003). Bioremediation Of Crude Oil Contaminated Soil By Bioaugmentation Of Pseudomonas Fluorescens Ns1. Journal Of Environmental Science And Health, Part A, 38, 1857-1866.

Britannica. 2018. Crude Oil [Online]. Encyclopædia Britannica Inc. Available: Https://Www.Britannica.Com/Science/CrudeOil [Accessed May 13, 2019].

Cameotra, S. S. \& Singh, P. (2008). Bioremediation Of Oil Sludge Using Crude Biosurfactants. International Biodeterioration \& Biodegradation, 62, 274-280.

Chisti, Y. \& Jauregui-Haza, U. J. (2002). Oxygen Transfer And Mixing In Mechanically Agitated Airlift Bioreactors. Biochemical Engineering Journal, 10, 143-153.

Cohen, Y. (2002). Bioremediation Of Oil By Marine Microbial Mats. International Microbiology, 5, 189-193.

Colwell, R. R., Walker, J. D. \& Cooney, J. J. (1977). Ecological Aspects Of Microbial Degradation Of Petroleum In The Marine Environment. Crc Critical Reviews In Microbiology, 5, 423-445.
Das, K. \& Mukherjee, A. K. (2005).

Characterization Of Biochemical Properties And Biological Activities Of Biosurfactants Produced By Pseudomonas Aeruginosa Mucoid And NonMucoid Strains Isolated From HydrocarbonContaminated Soil Samples. Applied Microbiology And Biotechnology, 69, 192-199.

Das, K. \& Mukherjee, A. K. (2007). Crude Petroleum-Oil Biodegradation Efficiency Of Bacillus Subtilis And Pseudomonas Aeruginosa Strains Isolated From A Petroleum-Oil Contaminated Soil From North-East India. Bioresource Technology, 98, 1339-1345.

Hanson, K., Nigam, A., Kapadia, M. \& Desai, A. J. (1997). News \& Notes: Bioremediation Of Crude Oil Contamination With Acinetobacter Sp. A3. Current Microbiology, 35, 191-193.

Higgins, I. \& Gilbert, P. (1978). The Biodegradation Of Hydrocarbons. The Oil Industry And Microbial Ecosystems, 80-114.

Kilonzo, P. M., Margaritis, A., Bergougnou, M., Yu, J. \& Qin, Y. (2006). Influence Of The Baffle Clearance Design On Hydrodynamics of A Two Riser Rectangular Airlift Reactor With Inverse Internal Loop And Expanded GasLiquid Separator. Chemical Engineering Journal, 121, 17-26.

Leahy, J. G. \& Colwell, R. R. (1990). Microbial Degradation Of Hydrocarbons In The Environment. Microbiology And Molecular Biology Reviews, 54, 305-315.

Lin, T.-C., Pan, P.-T. \& Cheng, S.-S. (2010). Ex Situ Bioremediation Of Oil-Contaminated Soil. Journal Of Hazardous Materials, 176, 27-34.

Lizardi-Jiménez, M., Leal-Bautista, R., Ordaz, A. \& Reyna-Velarde, R. (2015). Airlift Bioreactors For Hydrocarbon Water Pollution Remediation In A Tourism Development Pole. Desalination And Water Treatment, 54, 44-49.

Luttmann, R., Buchholz, H., Zakrzewski, W. \& Schügerl, K. (1982). Identification Of Mass-Transfer Parameters And Process Simulation Of Scp Production Process In Airlift Tower Reactors With An External Loop. Biotechnology And Bioengineering, 24, 817835. 
Martin, I., Wendt, D. \& Heberer, M. (2004). The Role Of Bioreactors In Tissue Engineering. Trends In Biotechnology, 22, 80-86.

Mehrasbi, M., Haghighi, B., Shariat, M., Naseri, S. \& Naddafi, K. (2003). Biodegradation Of Petroleum Hydrocarbons In Soil. Iranian Journal Of Public Health, 28-32.

Mishra, S., Jyot, J., Kuhad, R. C. \& Lal, B. (2001). Evaluation Of Inoculum Addition To Stimulate In Situ Bioremediation Of OilySludge-Contaminated Soil. Appl. Environ. Microbiol., 67, 1675-1681.

Mulligan, C. N. (2005). Environmental Applications For Biosurfactants. Environmental Pollution, 133, 183-198.

Nikolopoulou, M., Pasadakis, N. \& Kalogerakis, N. (2007). Enhanced Bioremediation Of Crude Oil Utilizing Lipophilic Fertilizers. Desalination, 211, 286-295.

Nwankwegu, A. S., Orji, M. U. \& Onwosi, C. O. (2016). Studies On Organic And In-Organic Biostimulants In Bioremediation Of DieselContaminated Arable Soil. Chemosphere, 162, 148-156.

Ogbonna, J. (2013). Industrial Biotechnology, Fundamental And Bioprocess Engineering For Biotechnological Production Of Useful Metabolites. Isebu Printing And Publishing Company Amakubo, 2-11.

Omotayo, A., Ojo, O. \& Amund, O. O. (2012). Crude Oil Degradation By Microorganisms In Soil Composts.
Paek, K., Chakrabarty, D. \& Hahn, E. 2005. Application Of Bioreactor Systems For Large Scale Production Of Horticultural And Medicinal Plants. Liquid Culture Systems For In Vitro Plant Propagation. Springer.

Ron, E. Z. \& Rosenberg, E. (2014). Enhanced Bioremediation Of Oil Spills In The Sea. Current Opinion In Biotechnology, 27, 191194.

Thavasi, R., Jayalakshmi, S. \& Banat, I. M. (2011). Effect Of Biosurfactant And Fertilizer On Biodegradation Of Crude Oil By Marine Isolates Of Bacillus Megaterium, Corynebacterium Kutscheri And Pseudomonas Aeruginosa. Bioresource Technology, 102, 772-778.

Thomassin-Lacroix, E., Eriksson, M., Reimer, K. \& Mohn, W. (2002). Biostimulation And Bioaugmentation For On-Site Treatment Of Weathered Diesel Fuel In Arctic Soil. Applied Microbiology And Biotechnology, 59, 551-556.

Whang, L.-M., Liu, P.-W. G., Ma, C.-C. \& Cheng, S.-S. (2008). Application Of Biosurfactants, Rhamnolipid, And Surfactin, For Enhanced Biodegradation Of DieselContaminated Water And Soil. Journal Of Hazardous Materials, 151, 155-163. 